\title{
Study on the Business Model and Value Creation of Internet Finance Based on Credit Construction
}

\author{
Hu Jing \\ Anhui Technical College of Industry and Economy, Anhui, Hefei, 230051, China \\ hujingah@126.com
}

Keywords: credit construction; Internet finance; business model; value.

\begin{abstract}
With the development and perfection of Internet technology and Internet infrastructure, the development of Internet finance has more advantages, which has promoted the prosperity and development of financial industry. Internet finance effectively breaks the inadequacy of the separation of enterprises from the market by economic theory, and forms a new financial operation system. In order to gain advantages in the fierce competition, it is necessary to actively carry out business model innovation, value creation, and regulatory policy for Internet banking development process, from the perspective of credit analysis of the construction of business model and value of Internet financial creation, give full pay to the Internet banking.
\end{abstract}

\section{Introduction}

The combination of Internet and Finance aims to achieve better and more convenient realization of matching funds providers and demand partners with Internet technology and thinking. The business model of Internet finance mainly includes fund raising, financial management and financial information service and so on. With the help of information processing capability and organization mode, Internet finance effectively reduces the cost of financial transaction and expands the scope of financial services. However, the lack of a clear way to make profits requires some business mode support.

\section{Analysis of credit construction}

\subsection{The general goal of credit construction}

According to the requirements of the socialist market economy system, we should establish a perfect, standardized and effective credit system, and adopt credit system, credit record, credit supervision and other means to maintain the growth of corporate credit in the development of [1]. On the one hand, enterprises should face the market, improve the credit level of enterprise credit management, good regulatory constraints and incentive mechanism; on the other hand, should strictly follow the legal framework, according to the orderly principle, the banking system, credit guarantee and business registration inspection system for construction enterprises to play out, subject, social service the credit system, improve the overall level of enterprise credit.

\subsection{The principle of credit construction}

First, we should follow the principle of marketization, adhere to the principle of "government promotion and market operation", and complete the production, exchange and consumption process of credit products with the help of market power. Secondly, we should also follow the principle of the rule of law, because the market economy is an economy ruled by law, so enterprises should follow the principle of the rule of law in the credit construction, in strict accordance with the national laws and regulations related to the implementation of the right, and make full use of the central government to give the regional ethnic autonomy, combined with the actual situation to develop suitable areas 
related to the actual the construction of credit laws and regulations, promote the credit status of the construction of rule of law, [2]. Enterprise credit construction should follow the principle of system, credit construction is a complicated system engineering, which requires all departments and localities, actively mobilize the enthusiasm of their cooperation, so as to better promote the construction of credit; it should also be comprehensive management system of credit standards, credit evaluation, credit information exchange and credit market management so, the overall advance [3]. Finally, the enterprise credit construction should adhere to the principles of fairness and justice, especially in the aspects of credit evaluation should follow the implementation of the principles of justice, avoid because of some economic benefits distort the evaluation results, the punishment for credit market supervision and dishonest behavior should also adhere to fair and open principles, improve the overall level of credit.

\subsection{The main task of credit construction}

The primary task of the construction of credit culture construction, which is the fundamental link of the construction of enterprise credit, honesty culture construction is an arduous and long-term task, so we should establish a long-term vision, adhere to honest and trustworthy man, work principle, carry forward the cultivation of credit culture, build honest and trustworthy enterprise core culture. Then we should carry out laws and regulations, gradually improve the rule of law and rule of law spirit, establish credit evaluation standards and information platform, build credit promoting maintenance mechanism, cultivate credit awareness and ability, and build a good credit environment.

\section{The business model of Internet Finance Based on credit construction}

\subsection{General payment platform}

An important symbol of Internet financial innovation is a safe and efficient modern payment system. Compared with the general payment platform with Alipay and other payment methods, its meaning is flexible and can provide two times the development of payment and settlement infrastructure to customers. The payment platform target customers of e-commerce enterprises and financial enterprises, develop new payment channels and enterprise payment service provider, payment platform support in this case, the customer can easily be integrated into their payment function in the business process, can also be developed to create their own professional and more flexible payment service. Development, sale and operation platform service is the key business of universal payment platform. The access qualification of access to the underlying clearing and settlement network is the key resource, and application developers and related businesses are the key partners. The main way to obtain income from the platform is to pay the service fee of the customer.

\subsection{Mobile P2P payment}

Mobile P2P payment service is the basic service of Internet finance. This kind of service charges much in the traditional financial system, and it is also very inconvenient to use. After building the new $\mathrm{P} 2 \mathrm{P}$ payment service system, the Internet effectively reduced the cost of services and transaction costs, and effectively incorporated into the crowd who had been excluded from financial services, and increased the sustainable development power of the regional economy. The target customers of mobile P2P payment are low-income group without financial account and small and micro businesses. These customers can make more convenient and less local transfer and payment with the help of the system, so as to enhance the efficiency of the entire financial and economic system [4]. This system can also establish a convenient, efficient and low-cost P2P payment platform and business acceptance network, ensure smooth operation of capital transfer, and provide financial value-added services on this basis, and actively develop user groups to form scale effect. The key resources of the business mode are payment service access qualification, liquidation infrastructure and the ability to provide financial value-added products. The business agent network, the relevant financial institutions and the government regulation department are the key partners. The cost mode of this payment mode 
mainly includes platform development and operation fee, publicity and promotion fee and receiving network construction fee, etc. the main source of income is service commissions and value-added services revenue sharing.

\subsection{Internet P2P credit}

The Internet using the Internet to build personal credit credit P2P platform, is a concrete manifestation of financing business disintermediation, if this business is properly carried out, to achieve effective allocation of funds more time and space to. The value connotation of the platform is lending and borrowing to give users a suitable cost of capital, its target customers are mainly investors and lenders, which investors can get higher than the traditional financial products, capital returns, lenders can also be more convenient, low cost to obtain funds. The key is to provide credit services of Internet P2P online fund supply and demand matching, credit evaluation, risk supervision and so on, which is a key resource platform of business processes, customer data and talent team, depth of key business partners according to the platform, is the main payment platform and related financial institutions. The cost of the platform is mainly to build online system, operation and marketing expenses, etc. the revenue comes from the transaction cost and the cost of the partners.

\subsection{Personal online financial management}

The main connotation of personal online financial management is to provide more convenient and transparent channels for customers, to make payments and investment management for customers. The target customers of this business mode are young middle class groups. These customers hope to make use of the Internet to manage revenue and expenditure dynamically and realtime, optimize their personal consumption structure, improve their asymmetric information on financial products, and broaden personal financing channels. The key business of this financial model is the online platform for development, operation and marketing, and provides the analysis, optimization, search and decision support of financial data. Personal financial data and data analysis, financial talents are key resources, and key partners are related to financial products and service providers, such as online banking, credit card and securities companies. The cost of the operating platform is mainly the development, sale and operation platform, and the income comes from the service of the customer, the advertising and the sharing of the partners.

\subsection{Big financial data}

With the further development of networking and digitalization, financial services gradually return to their essence, which is mainly reflected in the production, exchange, storage, analysis and application of financial data streams. The scale of financial data expands rapidly with the popularity of Internet, and its structure is becoming more and more complex. Through research and investigation, we find that big data has the highest value creating opportunity in the financial industry. This big data business needs specialized partners to provide [5]. The financial big data service value is given a new function and customer service, solve the traditional methods can not solve the problem, its target customers are all types of financial institutions; the key business of the business model is to provide large data storage services, personnel training and one-stop outsourcing services, key resources and partners are under the leadership of big data analyst the team of experts, the original data and related hardware and software service providers. The operating cost of the platform is the cost of hardware and software, the cost of data acquisition, and the Commission of service fees paid by the partners. The income comes from the income of the sales product and the charge for the service.

\section{The value creation of Internet Finance Based on credit construction}

\subsection{Promoting the benefit of financial services and improving the efficiency of the market}

To promote inclusive financial services is an important pole of consumer finance, diversified financial services subject is focused on the analysis of consumer behavior, with big data, cloud 
computing and mobile internet terminal support, a large number of processes, products and services innovation, will dig out the potential market to extend financial services and resources circulation channel to the bottom end of the market the vast rural areas. The single line of credit online consumer financial products are generally not more than 50 thousand yuan, most are less than million, consumer credit approval rate is also very fast, without collateral and guarantees to third parties, many small, scattered, there is no guarantee and mortgage the low-end users can also enjoy the modern financial services, so it can not balance improve the developed and underdeveloped areas, rural and inter city consumer finance development, promoting the real economy development and increasing employment, promoting social fairness. And combined with the analysis of the theory of life cycle hypothesis shows that liquidity constraints will affect the current consumption of consumers, and consumers will make optimal allocation of its life endowment and income implementation of each period of consumer spending, to achieve maximum utility [6]. The development of consumer finance can effectively alleviate liquidity constraints, improve consumer utility, and reduce transaction costs. Savings and investment income can be transformed into consumption expenditure at any time, consumption conditions have been effectively improved, and financial universality has been realized.

\subsection{Creating shared value and increasing the right to speak of consumers}

With the rapid development of Internet technology, Internet consumers increasingly prominent, the liberation of the rights of consumers, but also in the mobile Internet business environment, consumers can whenever and wherever possible and gradually become the consumption of goods and service publish and share information. Consumers can implement online shopping 24 hours a day, and the consumption space of consumers is also gradually expanding. Through mobile terminals, WeChat, micro-blog and other ports can enter online shopping mall. The growing popularity of mobile Internet consumers in case of discourse power was gradually improved, such as Amazon, Baidu, Ali and Tencent and other Internet companies, these enterprises effectively and greatly extend the consumer society the behavior of individual [7], consumer identity changes also appear in this process, can direct dialogue between producers, set up directly the relationship between producers and consumers and enterprises create new dynamic mechanism, the Internet financial industry to create a more updated value.

\subsection{Allocation of funds with more banks and network payment enterprises}

Before participating in Internet financial activities, users can ensure that funds can achieve barrier free circulation online. In order to make more Internet users more easily participate in Internet financial activities, Internet financial enterprises should actively interconnect with more banks. Because the bank will generate resentment of rival Internet financial enterprises, the Internet companies should actively seek with Alipay, caifutong and three party payment companies, to ensure their accessibility to mobile user network. In order to secure funds, the Internet financial enterprises should cooperate with the banks and the three party enterprises to build a safe and efficient Internet financial environment.

\section{Conclusions}

Compared with traditional finance, Internet finance is a new financing mode. It is a kind of third party financing mode. It flourished with the development of Internet information technology, which has increased the vitality of economic development and brought great convenience to people's life and production. The development of Internet banking needs of the relevant departments of supervision, to credit construction, so we should view credit construction business model analysis and to explore the value of Internet financial creation, explore new business models and a variety of ways and channels to create value, promote the prosperity and development of Internet banking. 


\section{Acknowledgements}

The general project of Humanities and social sciences research project in Anhui higher education institutions: the development status and Countermeasures of personal financing business of commercial banks under the Internet financial mode, 2017sk06.

\section{References}

[1] Zeng Xueyun, Business model and value from the Internet financial credit construction to create [J]. finance and accounting, 2017 (6): 29-32.

[2] Li Caifeng. Internet financial risk assessment based on structural equation model [D]. Harbin University of Science and Technology, 2017.

[3] Luo Xin. Research on Internet financial innovation based on the business model perspective [D]. Southwestern University of Finance and Economics, 2014.

[4] Cao Xiaoxiong. Consideration and Discussion on the construction of Internet financial service system by commercial banks, [J]. rural finance research, 2013 (5): 54-58.

[5] Wu Zhao. Research on the development strategy of small and medium commercial banks under the background of Internet financial business model [D]. Southwestern University of Finance and Economics, 2014.

[6] Sun Hao. The emerging business model of Internet Finance [J]. China credit card, 2013 (9): 50-54.

[7] Chen Rui, Chen Rui. Internet Age business model innovation: Based on the resource patchwork angle [J]. Shandong textile economy, 2017 (10): 49-52. 